\title{
Optimal Workfare in a Society of Workers and Non-Workers*
}

\author{
Claus Thustrup Hansen and Torben Tranæs \\ University of Copenhagen and EPRU ${ }^{\dagger}$
}

December 1999

\begin{abstract}
This paper studies the unemployment insurance and redistribution policy of a government who contemplates using workfare. We consider a population composed of employed and unemployed workers as well as individuals who do not seek employment (non-workers). Job search behavior is private information implying that non-workers can claim UI benefits rather than the social assistance they are eligible for. As a consequence, optimal pecuniary UI schemes underinsure workers against unemployment. We show that requiring unproductive activities in exchange for UI benefits (workfare) can Pareto improve welfare by facilitating better unemployment insurance, and we characterize the situations where this is the case.
\end{abstract}

Keywords: Workfare, Unemployment Insurance, Redistributive Policy JEL Classification Numbers: H2, J65

\footnotetext{
*Acknowledgments: We wish to thank Claes Bengtsson, Martin Browning, Peter Fredriksson, Nils Gottfries, Bertil Holmlund, Ann-Sofie Kolm, Donald Parsons, and seminar participants at the EEA'99 Congress and IFAU, Uppsala for comments and discussions. In particular we wish to thank Sören Blomquist for suggestions that changed the focus of the paper. Finally, the first author gratefully acknowledges the hospitality of IFAU. Correspondence: Institute of Economics, University of Copenhagen, Studiestraede 6, DK1455 Copenhagen K, Denmark. Ph.: +45 353230 20, fax: +45 353230 00, e-mail: claus.thustrup.hansen@econ.ku.dk and torben.tranaes@econ.ku.dk.

†The activities of EPRU (Economic Policy Research Unit) are financed through a grant from the Danish National Research Foundation.
} 


\section{Introduction}

The use of workfare is no longer restricted to poverty alleviation programs but is now applied in relation to joblessness in general. In the U.S. many unemployment insurance (UI) experiments include elements of effort requirements, e.g., recipients of UI benefits have to show up at the Employment Service frequently or participate in part-time courses on how to search and apply for jobs (see Meyer, 1995). Activities like these expropriate time from unemployed workers and thus reduce their current utility, independently of whether their job search skills improve. This is also the case in most European countries where participation in Active Labor Market Programs is now compulsory for UI recipients: ${ }^{1}$ to continue receiving UI benefits after a certain period of unemployment simply requires that recipients submit to the effort requirements of these programs. If we define "workfare" as benefits given conditionally on the recipients fulfilling some obligations, workfare is, in effect, being introduced into UI schemes, implying that the average worker is now a target for workfare.

Is there an economic argument for using workfare in relation to groups that are neither poor nor have weak abilities? We address this question by analyzing whether it is optimal for a benevolent government to use unproductive workfare as part of an unemployment insurance and redistribution policy when some individuals prefer not to work and when job search behavior is private information. $^{2}$

\footnotetext{
${ }^{1}$ The countries of the European Union have committed themselves to require work or educational effort in return for UI benefits after the first year of unemployment (The European Council, 1997). In many countries participation in Active Labor Market Programs has been required for years but without actually being enforced. E.g., the Netherlands did not start to sanction people who did not participate before 1992 (van den Berg et al., 1998).

${ }^{2}$ In almost all countries UI is provided by the government. A few countries do have union-administrated insurance funds but they are subsidized to such an extent that they are nearly indistinguishable from government-administrated systems (see Holmlund, 1998). There is of course no need for workfare if the government can distinguish between those who want to work and those who won't. In general, UI benefit recipients are required to
} 
There are many reasons why an individual may strictly prefer not to work at some point in time; child birth, education start, or simply because he or she has worked "too much" lately. Thus, at any given point in time there are individuals who are not interested in paid work at any realistic wage rate - for a while at least. ${ }^{3}$ These voluntarily jobless individuals (nonworkers) may, nevertheless, claim unemployment benefits when monitoring of job search behavior is imperfect. ${ }^{4}$ This kind of adverse selection can explain the absence of privately provided unemployment insurance as shown by Chiu and Karni (1998). In the publicly provided benefit system we study, adverse selection implies that it is optimal to underinsure individuals against unemployment. In this situation a government may chose to use workfare as a device to separate workers and non-workers and thereby provide better unemployment insurance for the labor force. In fact, this may Pareto improve the government's unemployment insurance and redistribution policy.

The intuition for why the exchange of benefits for worthless activities can enhance efficiency is the following. Consider a purely pecuniary benefit system where non-workers claim social assistance. Then suppose we raise UI benefits and require just enough work effort in exchange so that non-workers are indifferent between the old and the new UI scheme, and thus still do not sign up for UI benefits. Workers, on the other hand, may prefer the new UI scheme since they dislike work less than non-workers; specifically, if the increase in a worker's expected utility due to a smoother income stream is larger than the expected forgone leisure due to workfare, workers strictly

search but experiences from the last decades have shown that monitoring of job search behavior is bound to be limited.

${ }^{3}$ The labor force participation rates for the major OECD countries in the late 1990's were around 0.80; a little higher for the U.S. and a little lower for OECD-Europe (OECD, 1998).

${ }^{4}$ There are some indications that this actually happens. For instance, in the Netherlands and Denmark in the early nineties only $55 \%$ and $60 \%$, respectively, of benefit recipients indicated that they wanted a job and were actively searching for one (see Angenent, Bommeljé, and Schep, 1993; Pedersen and Smith, 1995). See also the discussion in Karni (1999). 
prefer the new scheme which therefore represents a Pareto improvement.

In general, any pecuniary unemployment insurance and social assistance benefit system is Pareto dominated by a benefit system with workfare if individuals have sufficiently different tastes for work. If individuals have the same disutility of work, it is never optimal to require that UI benefit recipients spend a certain number of hours on workfare activities in exchange for their benefits (time workfare). In this case it may, nevertheless, be optimal to require that the recipients perform a specific task in exchange for benefits (task workfare), namely when individuals' productivity differs. Moreover, we show that, in general, the use of task workfare Pareto dominates the use of time workfare. Finally, we conclude that the welfare argument for using workfare is stronger when there is less redistribution of income from workers to non-workers.

Until recently, workfare was only used in poverty alleviation programs, where the challenge is to give transfers to those with poor abilities without making it attractive for those with more fortunate abilities to also claim these transfers. It is often suggested that these more fortunate types could be discouraged from doing so if benefits were accompanied by a work requirement. However, the overall conclusion from the literature on poverty alleviation and redistribution (see Besley and Coate, 1992, 1995; Brett, 1998; Beaudry and Blackorby, 1998; Cuff, 1998) is that workfare is not an obvious means to securing a minimum utility level for all, unless workfare involves some kind of net product to society (it can be used though to provide a minimum income level for all, which disregards the disutility of performing workfare activities). Only if individuals differ with respect to both abilities and tastes for work can it be optimal to use workfare in poverty alleviation programs, and effort is then required of those with low ability and low work-disutility (see Beaudry and Blackorby, 1998; Cuff, 1998). ${ }^{5}$ By contrast the optimality

\footnotetext{
${ }^{5}$ It is difficult to make Pareto improvements by using workfare in poverty alleviation
} 
of using workfare as a screening device in unemployment insurance schemes depends only on heterogeneity along one dimension. Notice here that the screening problem we analyze is the reverse of the screening problem studied in poverty alleviation. In our analysis, workfare is used to prevent voluntary jobless individuals on social assistance from taking the UI package intended for unemployed workers. ${ }^{6}$

The next section presents the model. The third section derives the optimal benefit policies and characterizes when pecuniary benefit systems are dominated by workfare benefit systems. The last section makes some final remarks.

\section{The Model}

In this section we set up the model and describe the problem of a benevolent government that wishes to design an optimal benefit system consisting of unemployment insurance (UI) for individuals inside the labor force and monetary transfers from those in the labor force to those outside the labor force (we label these transfers social assistance, SA). The government cannot observe neither individual characteristics nor whether an individual has obtained a job offer.

\section{The timing of events}

First, each individual decides whether or not to join the labor force. Second, all members of the labor force receive a job offer with probabil-

programs, since in these programs workfare is used to increase the level of transfers from workers to non-workers.

${ }^{6}$ Of course, there are very few empirical studies of the effect of this new policy of requiring effort from UI recipients but there are some. Meyer (1995) evaluates a number of UI experiments some of which have an effort requiring element to them and find that this can easily influence the take up rate. The most direct evidence is due to Black, Berger, Noel, and Smith (1999). They are able to identify a sharp increase in the early exit from UI for recipients who face effort requirements. What triggers the exits seems to be the letter which informs recipients that the continuation of their benefits is conditional upon their participation in certain programs. 
ity $\rho \in(0,1)$. Those who receive a job offer either accept or reject and if they reject they remain jobless. Individuals who either rejected a job offer or who did not get an offer are unemployed (voluntary and involuntary, respectively) and can claim unemployment compensation, which is a package $\left\{b, \ell^{e}\right\}$, consisting of a monetary transfer, $b$, and an effort requirement, $\ell^{e}$, measured in time units. A pecuniary UI scheme has $\ell^{e}=0$ and a workfare UI scheme has $\ell^{e}>0$. Hence, to collect benefits under a workfare scheme, unemployed individuals have to spend a certain amount of time on workfare activities (time workfare). Alternatively, it may be possible to require a specific task performed by UI recipients in exchange for benefits (task workfare); this is analyzed in Section 3.3. Those outside the labor force receive social assistance, $\underline{b} \leq b$, and, without loss of generality, we assume that $\underline{b}$ is not accompanied by any effort requirements. ${ }^{7}$

\section{Individual Characteristics}

We consider a population composed of individuals of different types. The utility of an individual of type $i$ is given by

$$
u_{i}=v\left(I_{i}-\phi_{i} \ell_{i}\right)
$$

where $I_{i}$ is net-income, $\ell_{i}$ is forgone leisure, and $\phi_{i}$ represents valuation of leisure relative to income which may differ between types. This implies that the incentives to work are high for a given $I_{i}$ and $\ell_{i}$ when $\phi_{i}$ is low. We assume that the utility function, $v$, is twice continuously differentiable, strictly increasing, strictly concave, and fulfills the inada-condition $\lim _{x \rightarrow 0} v^{\prime}(x)=\infty$. An employed individual of type $i$ earns a net-income of $\omega_{i}-t$ per unit of working time where $\omega_{i}$ is an exogenous wage rate and where $t$ is a tax on employed individuals used to finance the benefit system. Since income and

\footnotetext{
${ }^{7}$ It will be clear later that it is never Pareto optimal to require effort of those outside the labor market. It would be possible to reduce the effort requirement and the benefit level of those working keeping their utility fixed while increasing utility of those not working through a lowering of the tax rate.
} 
leisure are perfect substitutes, the labor supply, $\ell_{i}$, is either zero hours or the maximum number of hours, normalized to one.

We are interested in the design of benefit systems in situations where some individuals prefer not to work. For simplicity we assume there are only two types of individuals, workers, $W$, and non-workers, $N$, where $\eta$ and $1-\eta$ are the fractions of these two types respectively in the population (with $0<\eta<1$ ), and where non-workers' net utility from working is less than their net utility from SA, that is, $\omega_{N}-\phi_{N}<\underline{b}$. Moreover, we assume $\omega_{W} \geq \omega_{N}$ and $\phi_{W} \leq \phi_{N}$ implying that non-workers are not more eager to work than workers.

\section{The Government's Problem}

The government knows the distribution of individual characteristics but cannot observe neither the characteristics of any particular individual nor whether an individual has received a job offer. This imposes some restrictions on which policies the government can implement.

First, the government needs to make sure that workers prefer employment to unemployment, implying that a benefit policy has to fulfill

$$
v\left(\omega_{W}-t-\phi_{W}\right) \geq v\left(b-\phi_{W} \ell^{e}\right)
$$

as it is impossible to observe whether a worker has rejected a job offer in order to claim UI benefits. If equation (1) does not hold, the only benefit system that can exists is the trivial one with $t=b=\underline{b}=0$.

Secondly, the government's benefit policy needs to be incentive compatible. The model may have either a separating or a pooling equilibrium depending on whether non-workers choose the SA or the UI package. However, it is sufficient to focus only on the separating equilibrium where non-workers prefer to be outside the labor market receiving $\underline{b}$ in SA. Therefore, we impose the incentive compatibility constraint

$$
v(\underline{b}) \geq v\left(b-\phi_{N} \ell^{e}\right)
$$


In a pooling equilibrium this constraint need not be fulfilled. Note, that it will never be optimal for the government to require workfare, i.e. $\ell^{e}=$ 0 , in a pooling equilibrium as this will reduce utility of both workers and non-workers. So formally, any optimal pooling equilibrium is a special case of a separating equilibrium where $b=\underline{b}$ and $\ell^{e}=0$, and it is therefore not excluded by the inequality (2). Thus, we can restrict attention to the separating equilibrium.

Finally, a benefit policy has to fulfill the budget constraint

$$
\eta[\rho t-(1-\rho) b]-(1-\eta) \underline{b} \geq 0,
$$

where the first term is the net expected revenue of workers and the last term is the cost of social assistance to non-workers.

\section{Optimal Benefit Policies}

We are interested in whether pecuniary benefit policies can be Pareto improved by introducing workfare. To analyze this, we maximize the ex ante expected utility of workers, $E\left(u_{W}\right)$, subject to a minimum utility level of non-workers, $\underline{u}$, that is, subject to

$$
u_{N}=v(\underline{b}) \geq \underline{u} .
$$

The existence of non-trivial benefit policies requires that workers prefer employment to unemployment and this gives an upper bound on $\underline{u}$. As $\underline{u}$ rises, taxes goes up and net income goes down for workers: when $\underline{u}$ rises above $\bar{u} \equiv v\left(\eta \rho\left[\omega_{W}-\phi_{W}\right]\right)$, workers no longer prefer to be employed and so there is no longer any tax revenue to finance transfers. ${ }^{8}$ Thus, the non-trivial cases are when $\underline{u} \in[0, \bar{u}]$.

\footnotetext{
${ }^{8}$ Suppose $\underline{u}=\bar{u}$ implying that $\underline{b} \geq \eta \rho\left[\omega_{W}-\phi_{W}\right]$. Then, under the cheapest benefit system, which is $b=\underline{b}=\eta \rho\left[\omega_{W}-\phi_{W}\right]$, the budget constraint implies that the employed worker obtains the same utility as an unemployed worker, that is $\omega_{W}-t-\phi_{W}=b$. Therefore, if $\underline{u}$ is raised above $\bar{u}$ then the benefit policy is impossible to implement, since workers prefer to be unemployed. Thus, there exists no solutions with redistribution policies $\underline{u}>\bar{u}$.
} 
Given these bounds on $\underline{u}$, it follows that workers always prefer to join the labor force. Workers are therefore either employed or unemployed and thus face ex ante expected utility

$$
E\left(u_{W}\right)=\rho v\left(\omega_{W}-t-\phi_{W}\right)+(1-\rho) v\left(b-\phi_{W} \ell^{e}\right) .
$$

Now we can solve for (constrained) Pareto optimal policies by maximizing equation (5) subject to (4), and to the constraints that workers prefer to work, inequality (1), that non-workers prefer SA to the UI package, inequality (2), that spending has to be within the budget, inequality (3), and that all the chosen variables are non-negative. A solution to this problem is a benefit system characterized by $b, \underline{b}, t$, and $\ell^{e}$. If this solution contains a positive level of workfare, $\ell^{e}>0$, then we have identified a benefit system with workfare that Pareto dominates all pecuniary benefit systems given the redistribution policy implied by $\underline{u}$.

\subsection{Pecuniary Benefit Systems}

Before analyzing the desirability of using workfare in benefit schemes, it is worthwhile to characterize the optimal benefit system if workfare cannot be used, that is $\ell^{e}=0$. Thus, we maximize (5) subject to (1), (2), (3), (4), and $\ell^{e}=0$ with respect to $b, \underline{b}$, and $t$, which all have to be non-negative. This yields a unique solution given by (see Appendix)

$$
b=\underline{b}, \quad t=\underline{b} \frac{1-\rho \eta}{\rho \eta},
$$

and

$$
v(\underline{b})=\underline{u}, \quad \frac{v^{\prime}\left(\omega_{W}-t-\phi_{W}\right)}{v^{\prime}(b)}>\frac{1-\rho}{1-\rho+\frac{1-\eta}{\eta}},
$$

or

$$
v(\underline{b})>\underline{u}, \quad \frac{v^{\prime}\left(\omega_{W}-t-\phi_{W}\right)}{v^{\prime}(b)}=\frac{1-\rho}{1-\rho+\frac{1-\eta}{\eta}} .
$$

The UI benefit level equals the social assistance level since, according to the incentive compatibility constraint (2), it is impossible to separate the two 
types without workfare. From these equations it is possible to derive the optimal pecuniary benefit policy for every minimum utility level of non-workers $\underline{u} \in[0, \bar{u}]$, and thereby characterize the set of Pareto optimal pecuniary benefit policies.

Proposition 1 Pareto optimal pecuniary policies are characterized by $(i)$ a positive level of social assistance, $\underline{b}>0$, for all $\underline{u} \in[0, \bar{u}]$ and (iia) some but less than full insurance against unemployment, $0<b<\omega_{W}-t-\phi_{W}$, if $\underline{u}<\bar{u}$, or (iib) full insurance against unemployment, $b=\omega_{W}-t-\phi_{W}$, if $\underline{u}=\bar{u}$.

Proof. (i) This follows directly from the above equations when $\underline{u}>0$. If $\underline{u}=0$ then the result follows from equation (8) and the assumptions on the utility function. (iia) It follows from $(i)$ and equation (6) that $b>0$. It follows from (6) and (8) that $\omega_{W}-t-\phi_{W}>b$ when $v(\underline{b})>\underline{u}$ since $\eta<1$. When $v(\underline{b})=\underline{u}<\bar{u}$ then the result follows from the fact that $b=\omega_{W}-t-\phi_{W}$ when $\underline{u}=\bar{u}$, cf. result (iib), and that $b$ is strictly increasing in $\underline{u}$. (iib) This follows from equations (4), (6), and the definition of $\bar{u}$.

The first result states that it is always Pareto optimal to give non-workers a positive level of transfers even without a minimum utility requirement. So, even a government that has no redistributive concerns, formalized by having $\underline{u}=0$, finds it optimal to give non-workers benefits. The reason is simply that workers cannot get any unemployment insurance benefits without giving the same amount in transfers to non-workers. ${ }^{9}$

The reason why workers are only partly insured against unemployment is that more insurance implies higher transfers from workers to non-workers.

\footnotetext{
${ }^{9}$ Note, that it is always optimal to have some insurance as the marginal utility of insurance go towards infinity when $b \rightarrow 0$ due to the inada condition on the utility function. Without this condition it may be optimal to have no unemployment insurance as in Chiu and Karni (1998).
} 
With perfect insurance, the marginal loss of less insurance is zero (the envelope theorem), whereas the marginal gain is a direct increase in expected net income due to a reduction in tax-financed transfers to non-workers. Therefore, full insurance is never optimal.

\subsection{Workfare Benefit Systems}

Having characterized the Pareto optimal pecuniary benefit policies, we now turn to the main question of the paper: when can an optimal pecuniary benefit policy be Pareto improved by introducing workfare? In other words, we analyze whether, given some minimum utility requirement, $\underline{u}$, there exists a package $\left\{b, \ell^{e}\right\}$ with unproductive workfare, $\ell^{e}>0$, that Pareto dominates the best package without workfare. To do this, we maximize (5) subject to (1), (2), (3), and (4) with respect to $b, \underline{b}, t$, and $\ell^{e}$, which all have to be non-negative. The unique solution is characterized by (see Appendix)

$$
\begin{gathered}
\underline{b}=b-\phi_{N} \ell^{e}, \\
t=\frac{1}{\rho} \frac{1-\eta}{\eta} \underline{b}+\frac{1-\rho}{\rho} b,
\end{gathered}
$$

and

$$
v(\underline{b})=\underline{u}, \quad \frac{v^{\prime}\left(\omega_{W}-t-\phi_{W}\right)}{v^{\prime}\left(b-\phi_{W} \ell^{e}\right)}>\frac{1-\rho}{1-\rho+\frac{1-\eta}{\eta}},
$$

or

$$
v(\underline{b})>\underline{u}, \quad \frac{v^{\prime}\left(\omega_{W}-t-\phi_{W}\right)}{v^{\prime}\left(b-\phi_{W} \ell^{e}\right)}=\frac{1-\rho}{1-\rho+\frac{1-\eta}{\eta}},
$$

and

$$
\ell^{e}>0, \quad \frac{v^{\prime}\left(\omega_{W}-t-\phi_{W}\right)}{v^{\prime}\left(b-\phi_{W} \ell^{e}\right)}=1-\frac{\phi_{W}}{\phi_{N}},
$$

or

$$
\ell^{e}=0, \quad \frac{v^{\prime}\left(\omega_{W}-t-\phi_{W}\right)}{v^{\prime}(b)}>1-\frac{\phi_{W}}{\phi_{N}} .
$$

The first two equations follow from the incentive compatibility constraint (2) and the budget constraint (3) both being binding. The next two equations 
show that the minimum utility requirement may or may not be binding, which is what one should expect given the results in Section 3.1. Finally, the last equations reveal that workfare may or may not be part of a solution depending on the parameters of the model. From these equations, we get

Proposition 2 If and only if workers and non-workers differ sufficiently in their valuation of leisure, $\frac{\phi_{N}}{\phi_{W}}>\frac{1-\rho \eta}{1-\eta}$, there exists $\tilde{u} \in(0, \bar{u})$ such that for all minimum utility levels of non-workers $\underline{u} \in[0, \tilde{u}]$ any pecuniary benefit system is strictly Pareto dominated by a (time) workfare benefit system.

Proof. See Appendix.

Thus, unproductive workfare for unemployed workers may yield a Pareto improvement from an initial situation without workfare, and the scope for using workfare is larger, the smaller are the transfers from workers to nonworkers (i.e., the smaller is $\underline{u}$ ). Introducing workfare can only create a gain for workers if it is possible to raise their UI benefits, $b$, more than the utility loss inflicted upon them because of the effort they have to deliver when unemployed, $\phi_{W} \ell^{e}$. This is possible when non-workers value leisure more than workers. Then the effort requirement needs only be relatively small to discourage non-workers from joining the labor force such that the disutility inflicted on workers is relatively small as well. Hence, $b$ can increase more than $\phi_{W} \ell^{e}$. The proposition shows that the difference in valuation of leisure between workers and non-workers has to be sufficiently large, that is $\frac{\phi_{N}}{\phi_{W}}>$ $\frac{1-\rho \eta}{1-\eta}>1$, before it is optimal to use workfare.

If $\eta$ is large, then the fraction of non-workers in the population is small, implying that it is relatively cheap to have a high transfer level compared to the utility loss from workfare that has to be inflicted upon all unemployed workers in order to discourage the few non-workers from claiming UI benefits. In this case the difference in valuation of leisure has to be large for workers to prefer UI with workfare. 
On the other hand, if $\rho$ is large, then unemployment among workers is small, implying that the utility loss among workers of being on workfare is small relative to the number of non-workers discouraged from claiming UI benefits. Thus, a high $\rho$ reduces the required difference in valuation of leisure between the two types and makes workfare more preferable.

If the minimum utility requirement, $\underline{u}$, is high then transfers are high. This implies that the UI benefit level can be high before conflicting with the incentive compatibility constraint even without workfare. In this situation the marginal gain from more insurance is relatively small compared to the costs of higher taxes and when $\underline{u}$ becomes sufficiently large it is no longer optimal to use workfare. Furthermore, it follows that

Corollary 1 (Time) workfare is Pareto inefficient ( $i$ ) if workers and nonworkers differ only with respect to productivity, $\omega_{i}$, or $(i i)$ if the minimum utility requirement is equal to the maximal possible level, $\underline{u}=\bar{u}$.

Proof. Both $(i)$ and $(i i)$ follow directly from the above proposition.

The first result is best understood by looking at the incentive compatibility constraint (2) when $\phi_{W}=\phi_{N} \equiv \phi$. This gives $v(\underline{b})=v\left(b-\phi \ell^{e}\right)$ showing that a rise in $\ell^{e}$ only gives the possibility of raising $b$ so as to keep the utility of an unemployed worker unchanged. The only change then is an increase in the tax level, which unambiguously reduces the utility of the worker. Thus, it is never Pareto optimal to require a certain number of hours of work in exchange for benefits as a way of separating the two types when they only differ with respect to productivity.

When the minimum utility requirement is equal to the maximum possible level, $\underline{u}=\bar{u}$, the utility of non-workers and employed and unemployed workers are identical, even without effort requirement: $v\left(\omega_{W}-t-\phi_{W}\right)=v(b)=$ $v(\underline{b})$. In such a "perfectly equalitarian" society workfare is, of course, never 
optimal. Introducing effort requirement would make it possible to transfer more of the worker's income from periods of employment to periods of unemployment but they would not want that as they are already perfectly insured.

\subsection{Time Workfare vs. Task Workfare}

In the preceding analysis we have assumed that workfare is a time requirement (time workfare). It would, however, also be possible to require that benefit recipients perform a particular task. This would not change any of the previous results if both workers and non-workers use the same amount of time performing the task; that is, if the task is unrelated to their skills so that their productivity in an ordinary job is irrelevant.

Of course, there exist tasks that high productivity individuals can perform faster than low productivity individuals. If, for instance, the two types are both bricklayers, one faster than the other, the task could simply be laying bricks. If such tasks are required in exchange for benefits (task workfare) the previous results can be generalized.

Suppose that benefit recipients have to perform a specific task, $T$, for which their productivity in an ordinary job matters such that the time required to perform the task is given by

$$
\ell_{i}^{e}=T / \omega_{i}
$$

With this type of workfare Proposition 2 is replaced by

Proposition 3 If and only if workers and non-workers differ sufficiently with respect to productivity or valuation of leisure, $\frac{\phi_{N} / \omega_{N}}{\phi_{W} / \omega_{W}}>\frac{1-\rho \eta}{1-\eta}$, then there exists $\tilde{u} \in(0, \bar{u})$ such that for all minimum utility levels of non-workers $\underline{u} \in[0, \tilde{u}]$, any pecuniary benefit system is strictly Pareto dominated by a task workfare benefit system. 
Proof. The utility loss of a person in task workfare is $\phi_{i} \frac{T}{\omega_{i}}$ compared to $\phi_{i} \ell^{e}$ in time workfare. This implies that the proof of Proposition 2 applies if the terms $\phi_{i} \ell^{e}$ are replaced with $\phi_{i} \frac{T}{\omega_{i}}$ and the maximization is done with respect to $T$ instead of $\ell^{e}$.

Thus, the scope for using workfare is enlarged if it is possible to demand a specific task instead of a simple time requirement in exchange for benefits. In fact, contrary to time workfare, it may be Pareto optimal to use task workfare if workers and non-workers differ only with respect to productivity. This occurs if the productivity of workers is sufficiently higher than non-workers, specifically if $\frac{\omega_{W}}{\omega_{N}}>\frac{1-\rho \eta}{1-\eta}$. The intuition is simply that task workfare implicitly requires more time of less productive persons, implying that effort-contingent UI benefits are less attractive to non-workers than workers although they have the same valuation of leisure. Thus, task workfare is a better screening device than time workfare and in general we have

Corollary 2 Task workfare weakly Pareto dominates time workfare.

Proof. Assume $\omega_{W}>\omega_{N}$ and consider an optimal solution under time workfare $\left\{\ell^{e}, b, \underline{b}, t\right\}$ and a task workfare UI system where the task is set such that non-workers use the same amount of time on workfare in the two systems, $\ell_{N}^{e}=\ell^{e}$, implying that $T=\ell^{e} \omega_{N}$. Then $\ell_{W}^{e}=T / \omega_{W} \leq \ell^{e}$, implying that workers use less time on workfare under task workfare. Thus, the only difference is that less utility loss is inflicted on workers in workfare and consequently that task workfare Pareto dominates time workfare. If instead $\omega_{W}=\omega_{N}$ then the two systems are identical.

\section{Conclusion}

We have demonstrated that the use of workfare activities for UI recipients, as embedded in the latest labor market reforms and benefit experiments in 
many countries, may enhance welfare by facilitating better insurance against unemployment. UI recipients are required to perform specific tasks or to spend a certain amount of time in workfare in order to collect benefits, and these activities inflict disutility on the participants. To make our point more transparent, we have assumed that the activities themselves do not bring about any valuable product; nevertheless, they can (Pareto) improve a pecuniary benefit policy. ${ }^{10}$

If individual characteristics are known, the UI problem is straightforward: with risk adverse workers, the UI scheme should simply insure workers fully against unemployment and no workfare should be required. But when preferences and productivity are private information and job search behavior cannot be observed, the optimal UI does not yield full insurance; non-workers claim UI benefits so that only part of the tax revenue goes to unemployment compensation. This is when workfare becomes useful. If workers and non-workers have different preferences for leisure, the effort requirement of workfare is going to affect them differently. This may facilitate better income smoothing for workers by keeping non-workers from claiming UI benefits instead of social assistance. Thus, workfare may improve the benefit system in this case, and the smaller are the transfers from workers to non-workers, the stronger are the gains from using workfare. When transfers are high, workers can obtain a high UI benefit level without the use of workfare. The gains from additional insurance are therefore small and workfare becomes less preferable. On the other hand, when voluntary jobless individuals are not eligible for any kinds of benefits (i.e. $\underline{u}=0$ ), as is the situation in many countries, the case for using workfare to improve unemployment insurance is particular strong.

\footnotetext{
${ }^{10}$ The assumption that workfare activities are not productive is, of course, an extreme assumption. However, there are also substantial costs associated with setting up and running a workfare system. So strictly speaking, what we assume is that costs and benefits cancel out. If workfare provides a net product, there is, of course, much greater scope for using it (see Brett, 1998).
} 
We have also shown that it is never possible to (Pareto) improve a benefit system by the use of time requirements if workers and non-workers differ only with respect to productivity. ${ }^{11}$ In this case, (time) workfare is not a useful screening device, as workers and non-workers experience the same disutility of being on workfare. However, if specific tasks can be required then workfare may be part of an optimal benefit policy even when workers and non-workers differ only with respect to productivity. This arises because a task requirement is a better screening device, which also implies that it is better to base a workfare benefit system on task requirements than on time requirements. However, a task workfare system is probably more difficult to administer compared to a time workfare system. In time workfare, everybody just has to participate a certain number of hours in some workfare activities, whereas in task workfare a specific task needs to be devised for each type of skill, so that the unobserved productivity of recipients will determine different performing times for different productivity types. Thus, the gains from better screening when using a task workfare system should be balanced against the higher administrative costs in running such a system.

\footnotetext{
${ }^{11}$ This compliments the findings on workfare in poverty alleviation programs. Besley and Coate $(1992,1995)$ show that, when individuals differ only with respect to productivity, it is never Pareto optimal to use (time) workfare to discourage individuals with higher abilities from claiming benefits intended for those with low abilities. We show that it is also not optimal to use workfare to discourage low ability types from claiming UI benefits intended for high ability types.
} 


\section{A Derivation of the equations in Section 3}

The equations in Section 3.1 are a special case of the solution to the more general system in Section 3.2. Therefore, we turn directly to the general maximization problem. The problem is to maximize (5) with respect to $b$, $\underline{b}, t$, and $\ell^{e}$ subject to (1), (2), (3), (4), and the non-negativity requirements $b \geq 0, \underline{b} \geq 0, t \geq 0$, and $\ell^{e} \geq 0$. This can be rewritten as

$$
\max _{b, \underline{b}, t, \ell^{e}} H\left(b, \underline{b}, t, \ell^{e}\right)=\rho v\left(\omega_{W}-t-\phi_{W}\right)+(1-\rho) v\left(b-\phi_{W} \ell^{e}\right)
$$

subject to $b \geq 0, \underline{b} \geq 0, t \geq 0, \ell^{e} \geq 0$,

$$
\begin{aligned}
& g_{1}\left(b, \underline{b}, t, \ell^{e}\right)=\omega_{W}-t-\phi_{W}-\left[b-\phi_{W} \ell^{e}\right] \geq 0, \\
& g_{2}\left(b, \underline{b}, t, \ell^{e}\right)=\underline{b}-\left[b-\phi_{N} \ell^{e}\right] \geq 0, \\
& g_{3}\left(b, \underline{b}, t, \ell^{e}\right)=\eta[\rho t-(1-\rho) b]-(1-\eta) \underline{b} \geq 0, \\
& g_{4}\left(b, \underline{b}, t, \ell^{e}\right)=\underline{b}-\underline{b}(\underline{u}) \geq 0,
\end{aligned}
$$

where $\underline{b}(\underline{u}) \equiv v^{-1}(\underline{u})$ is the minimum level of social assistance implied by the minimum utility requirement. Note, that the objective function is strictly concave and that all constraints are linear. This implies that there exists a unique global constrained maximizer, which satisfies the Kuhn-Tucker conditions. The Lagrangian associated with the above problem is

$$
L\left(b, \underline{b}, t, \ell^{e}\right)=H\left(b, \underline{b}, t, \ell^{e}\right)+\sum_{j=1}^{4} g_{j}\left(b, \underline{b}, t, \ell^{e}\right)
$$

giving the following necessary conditions for a maximum

$$
\begin{gathered}
g_{j}\left(b, \underline{b}, t, \ell^{e}\right) \geq 0, \lambda_{j} \geq 0 \quad, \quad g_{j}\left(b, \underline{b}, t, \ell^{e}\right) \lambda_{j}=0 \quad \forall j, \\
\frac{\partial L}{\partial x_{i}} \leq 0 \quad, \quad x_{i} \geq 0 \quad, \quad x_{i} \frac{\partial L}{\partial x_{i}}=0 \quad \forall i .
\end{gathered}
$$

The derivatives are

$$
\frac{\partial L}{\partial b}=(1-\rho) v^{\prime}\left(b-\phi_{W} \ell^{e}\right)-\lambda_{1}-\lambda_{2}-\lambda_{3} \eta(1-\rho),
$$




$$
\begin{gathered}
\frac{\partial L}{\partial \underline{b}}=\lambda_{2}-\lambda_{3}(1-\eta)+\lambda_{4}, \\
\frac{\partial L}{\partial t}=-\rho v^{\prime}\left(\omega_{W}-t-\phi_{W}\right)-\lambda_{1}+\lambda_{3} \eta \rho, \\
\frac{\partial L}{\partial \ell^{e}}=-(1-\rho) \phi_{W} v^{\prime}\left(b-\phi_{W} \ell^{e}\right)+\lambda_{1} \phi_{W}+\lambda_{2} \phi_{N} .
\end{gathered}
$$

We now show that there always exists a solution fulfilling $\lambda_{1}=0, \lambda_{2}>0$, and $\lambda_{3}>0, \lambda_{4} \geq 0$. Then, due to uniqueness, any other combinations of binding and non-binding constraints are ruled out.

From equation (11), we get

$$
\lambda_{3}=\frac{v^{\prime}\left(\omega_{W}-t-\phi_{W}\right)}{\eta}>0 .
$$

Inserting $\lambda_{3}$ in equation (9) gives

$$
\frac{\partial L}{\partial b}=(1-\rho) v^{\prime}\left(b-\phi_{W} \ell^{e}\right)-\lambda_{2}-v^{\prime}\left(\omega_{W}-t-\phi_{W}\right)(1-\rho)=0
$$

$\Leftrightarrow$

$$
\lambda_{2}=(1-\rho)\left[v^{\prime}\left(b-\phi_{W} \ell^{e}\right)-v^{\prime}\left(\omega_{W}-t-\phi_{W}\right)\right] .
$$

It then follows that $\lambda_{2}>0$ if

$$
\omega_{W}-t-\phi_{W}>b-\phi_{W} \ell^{e}
$$

Note also, that if inequality (13) is fulfilled, then $g_{1}\left(b, \underline{b}, t, \ell^{e}\right)>0$, confirming that $\lambda_{1}=0$.

Inserting $\lambda_{2}$ and $\lambda_{3}$ into equation (10) and using the constraint $g_{2}\left(b, \underline{b}, t, \ell^{e}\right)=$ 0 yields

$$
\frac{\partial L}{\partial \underline{b}}=(1-\rho)\left[v^{\prime}\left(b-\phi_{W} \ell^{e}\right)-v^{\prime}\left(\omega_{W}-t-\phi_{W}\right)\right]-\frac{v^{\prime}\left(\omega_{W}-t-\phi_{W}\right)}{\eta}(1-\eta)+\lambda_{4}=0
$$

$\Uparrow$

$$
\lambda_{4}=\left[1-\rho+\frac{1-\eta}{\eta}\right] v^{\prime}\left(\omega_{W}-t-\phi_{W}\right)-(1-\rho) v^{\prime}\left(b-\phi_{W} \ell^{e}\right)
$$

$\Rightarrow \lambda_{4}>0$ if

$$
\frac{v^{\prime}\left(\omega_{W}-t-\phi_{W}\right)}{v^{\prime}\left(b-\phi_{W} \ell^{e}\right)}>\frac{1-\rho}{1-\rho+\frac{1-\eta}{\eta}} \quad \text { and } \quad v(\underline{b})=\underline{u},
$$


whereas $\lambda_{4}=0$ if

$$
\frac{v^{\prime}\left(\omega_{W}-t-\phi_{W}\right)}{v^{\prime}\left(b-\phi_{W} \ell^{e}\right)}=\frac{1-\rho}{1-\rho+\frac{1-\eta}{\eta}} \quad \text { and } \quad v(\underline{b})>\underline{u} .
$$

Inserting $\lambda_{2}$ into equation (12) yields

$$
\frac{\partial L}{\partial \ell^{e}}=\left(1-\frac{\phi_{W}}{\phi_{N}}-\frac{v^{\prime}\left(\omega_{W}-t-\phi_{W}\right)}{v^{\prime}\left(b-\phi_{W} \ell^{e}\right)}\right)(1-\rho) \phi_{N} v^{\prime}\left(b-\phi_{W} \ell^{e}\right)
$$

If $\frac{\partial L}{\partial \ell^{e}}=0$ then

$$
\frac{v^{\prime}\left(\omega_{W}-t-\phi_{W}\right)}{v^{\prime}\left(b-\phi_{W} \ell^{e}\right)}=1-\frac{\phi_{W}}{\phi_{N}} \quad \text { and } \quad \ell^{e}>0
$$

whereas, if $\frac{\partial L}{\partial \ell^{e}}<0$ then

$$
\frac{v^{\prime}\left(\omega_{W}-t-\phi_{W}\right)}{v^{\prime}(b)}>1-\frac{\phi_{W}}{\phi_{N}} \quad \text { and } \quad \ell=0 .
$$

We now show that there always exists a combination $\left(b, \underline{b}, t, \ell^{e}\right)$ fulfilling either (14) or (15) and at the same time fulfilling either (16) or (17). Using the budget constraint, $g_{3}\left(b, \underline{b}, t, \ell^{e}\right)=0$, and $b=\underline{b}+\phi_{N} \ell^{e}$ obtained from the constraint $g_{2}\left(b, \underline{b}, t, \ell^{e}\right)=0$, implies that the left hand side of (14) to (17) can be written as

$$
f\left(\underline{b}, \ell^{e}\right) \equiv \frac{v^{\prime}\left(\omega_{W}-\frac{1-\eta \rho}{\eta \rho} \underline{b}-\phi_{W}-\frac{1-\rho}{\rho} \phi_{N} \ell^{e}\right)}{v^{\prime}\left(\underline{b}+\left(\phi_{N}-\phi_{W}\right) \ell^{e}\right)},
$$

with the following properties: $f_{\underline{b}}^{\prime}\left(\underline{b}, \ell^{e}\right)>0, \lim _{\underline{b} \rightarrow 0} f(\underline{b}, 0)=0$, and $f_{\ell^{e}}^{\prime}\left(\underline{b}, \ell^{e}\right)>$ 0 .

Furthermore, note that for $\underline{u}=\bar{u}$ we have $\underline{b}=\eta \rho\left[\omega_{W}-\phi_{W}\right]$, which implies

$$
f\left(\eta \rho\left[\omega_{W}-\phi_{W}\right], 0\right)=1 .
$$

Since the right hand side of (14) to (17) is positive but below one, continuity of $f(\cdot)$ implies that there is always a solution fulfilling either (14) or (15) and also fulfilling either (16) or (17). Finally, note that $f\left(\underline{b}, \ell^{e}\right)<1$ whenever 
$\underline{u}<\bar{u}$, implying that inequality (13) is always fulfilled except for the limiting case where $\underline{u}=\bar{u}$. Now, the first two equations in Section 3.2 follow from $g_{2}\left(b, \underline{b}, t, \ell^{e}\right)=g_{3}\left(b, \underline{b}, t, \ell^{e}\right)=0$, whereas the rest of the equations are identical to the equations (14) to (17). The problem in Section 3.1 is identical to the problem in Section 3.2 with the only exception that $\ell^{e}$ is fixed at zero. Therefore, the equations in Section 3.1 can be derived directly by setting $\ell^{e}$ equal to zero in the relevant equations in Section 3.2.

\section{B Proof of Proposition 3}

Using (18) to rewrite equations (14) and (15), we have that

$$
f\left(\underline{b}, \ell^{e}\right)>\frac{1-\rho}{1-\rho+\frac{1-\eta}{\eta}} \quad \text { and } \quad v(\underline{b})=\underline{u}
$$

or

$$
f\left(\underline{b}, \ell^{e}\right)=\frac{1-\rho}{1-\rho+\frac{1-\eta}{\eta}} \quad \text { and } \quad v(\underline{b})>\underline{u},
$$

where $f\left(\underline{b}, \ell^{e}\right)$ is defined by equation (18).

Using (18) to rewrite equations (16) and (17), we have that

$$
f\left(\underline{b}, \ell^{e}\right)=1-\frac{\phi_{W}}{\phi_{N}} \quad \text { and } \quad \ell^{e}>0
$$

or

$$
f(\underline{b}, 0)>1-\frac{\phi_{W}}{\phi_{N}} \quad \text { and } \quad \ell^{e}=0 .
$$

It follows from equations (19) and (20) that $f\left(\underline{b}, \ell^{e}\right) \geq 1-\phi_{W} / \phi_{N}$. From the condition in the proposition we have that

$$
1-\phi_{W} / \phi_{N}>\frac{1-\rho}{1-\rho+\frac{1-\eta}{\eta}},
$$

implying that $v(\underline{b})=\underline{u}$.

Note that $f_{\underline{b}}^{\prime}\left(\underline{b}, \ell^{e}\right)>0, \lim _{\underline{b} \rightarrow 0} f(\underline{b}, 0)=0$, and $f_{\ell^{e}}^{\prime}\left(\underline{b}, \ell^{e}\right)>0$. Now, if $\underline{u} \rightarrow 0$ then $\underline{b} \rightarrow 0$ implying from equations (19) and (20) that the 
solution is characterized by $\ell^{e}>0$. On the other hand, if $\underline{u}=\bar{u}$ then $\underline{b}=\eta \rho\left[\omega_{W}-\phi_{W}\right] \Rightarrow$

$$
f\left(\eta \rho\left[\omega_{W}-\phi_{W}\right], 0\right)=1
$$

in which case (19) and (20) imply that $\ell^{e}=0$. Continuity then implies that there exists $\tilde{u} \in(0, \bar{u})$ such that $\ell^{e}>0$ for $\underline{u} \leq \tilde{u}$. QED. 


\section{References}

[1] Angenent, F. J. A., J. B. Bommeljé, and G. J. Schep (1993): "From Welfare to Work; about the Position in the Labor Market Instrument in Welfare" (in Dutch: "Straf of Stimulans? Het Toepassen van Sancties als Arbeidsmarktinstrument in de RWW"), VUGA Uitgeverij, 'sGravenhage.

[2] Beaudry, Paul and Charles Blackorby (1998): "Taxes and Employment Subsidies in Optimal Redistribution Programs." NBER Working Paper 6355.

[3] Besley, Timothy and Stephen Coate (1992): "Workfare versus Welfare: Incentives Arguments for Work Requirements in Poverty-Alleviation Programs." American Economic Review, 82, pp. 249-261.

[4] Besley, Timothy and Stephen Coate (1995): "The Design of Income Maintenance Programmes." Review of Economic Studies, 62, pp. 187221.

[5] Black, Dan A., Mark C. Berger, Brett J. Noel, and Jefferey A. Smith (1999): "Is Traning a Carrot or a Stick? Experimental Evidence from the UI System." Memo, Center for Policy Research, New York.

[6] Brett, Craig (1998): "Who Should Be on Workfare? The Use of Work Requirements as Part of an Optimal Tax Mix." Oxford Economic Papers, 50 (4), pp. 607-622.

[7] Chiu, W. Henry and Edi Karni (1998): "Endogenous Adverse Selection and Unemployment Insurance." Journal of Political Economy, 106 (4), pp. 806-827.

[8] Cuff, K. (1998): "Optimality of Workfare with Heterogeneous Preferences." Working Paper, Queen's University. 
[9] European Council (1997): "The Conclusions of the Executive Committee." The Meeting of the European Council in Luxemborg, November 1997.

[10] Holmlund, Bertil (1998): "Unemployment Insurance in Theory and Practice." Scandinavian Journal of Economics, 100 (1), pp. 113-41.

[11] Karni, Edi (1999): "Optimal Unemployment Insurance: A Survey." Southern Economic Journal, 66 (2), 442-465.

[12] Meyer, Bruce d. (1995): "Lessons from the U.S. Unemployment Insurance Experiments." Journal of Economic Literature, 33 (1), pp. 91-131.

[13] OECD (1998): The OECD Employment Outlook. Paris.

[14] Pedersen, Peder J. and Nina Smith (1995): "Search Activity Among Employed and Unemployed Members of the Workforce" in G. V. Mogensen (ed.): Work Incentives in the Danish Welfare State. Aarhus.

[15] Van den Berg, Gerard, Bas van der Klaauw, and Jan C. van Ours (1998): "Punitive Sanctions and the Transition Rate from Welfare to Work." Working Paper, Free University Amsterdam. 